\title{
THE USE OF METHYLENE BLUE AS AN INDICATOR IN IODIMETRIC TITRATIONS.
}

\author{
By FRANK STURDY SINNATT. \\ (Read at the Meeting, June 5, 1912.)
}

IN a previous publication (ANALYST, 1910, 35, 309) it was shown that a dilute aqueous solution of methylene blue may be used in place of starch as an indicator in iodimetric titrations. The determinations quoted in that publication were made with a solution of methylene blue prepared by dissolving pure methylene blue in water. It has since been found that the usual commercial forms of methylene blue may also be used without the delicacy of the colour change at the completion of the titration being interfered with. The solutions should be of a similar concentration to that suggested for the pure methylene blue-viz., 0.05 grm. per litre, and about 1 c.c. be taken for a titration. The following observations may be added to the previous note :

It will be found that the compound of iodine and methylene blue frequently separates from the solution as a precipitate. This occurs when an excessive amount of methylene blue has been added, but it will be found not to interfere with the observance of the colour change. There are no objections, such as hold in the case of starch, to the introduction of the methylene blue at the beginning of the titration, and no retardation of the change in colour has been observed.

Titrations have been made in order to determine the influence of inorganic compounds upon the behaviour of the indicator, and neutral salts and the following acids -acetic, hydrochloric, or sulphuric-have been found not to affect the colour change.

When a solution of iodine in alcohol or in aqueous potassium iodide solution is added to methylene blue dissolved in alcohol, the formation of the iodine compound of methylene blue is accompanied by the production of a green-coloured solution. The change in colour is delicate, and, although not very pronounced, is more easily observed than when no indjcator at all is used. The addition of a reducing agent such as sodium thiosulphate to the green solution restores the colour of the methylene blue. It is suggested that methylene blue may be of use for the determination of iodine in the presence of alcohol, where it would be impossible to use another indicator.

It has been shown by Harrison (Koll. Zeit., 1911, 9, 5) that the formation of the blue coloration when iodine solution is added to starch solution is interfered with by the introduction of ethyl alcohol. The volume of ethyl alcohol which prevents the formation of the blue coloration varies with the concentrations of the solutions, and in the experiments quoted the blue coloration was not definitely produced when 30 per cent. of alcohol by volume was present in the liquid. Before this percentage of alcohol is reached the formation of the blue compound is too indefinite to be of value as an indicator.

In order to test the value of methylene blue as an indicator in the presence of alcohol, the following determinations were carried out. The solutions used were sodium thiosulphate solution $(1$ c.c. $=0.01309 \mathrm{grm}$. iodine) made according to the 
usual directions, and starch solution made from pure potato starch. The ethyl alcohol contained 96 per cent. of alcohol by volume. In carrying out the check titrations with starch solution, sufficient water was added to lower the percentage of alcohol present to about 2 per cent. Generally three titrations were made for each experiment.

$\frac{N}{10}$ iodine solution (potassium iodide) was mixed with alcohol, 1 c.c. of methylene blue in alcoholic solution added, and the liquid titrated with sodium thiosulphate solution.

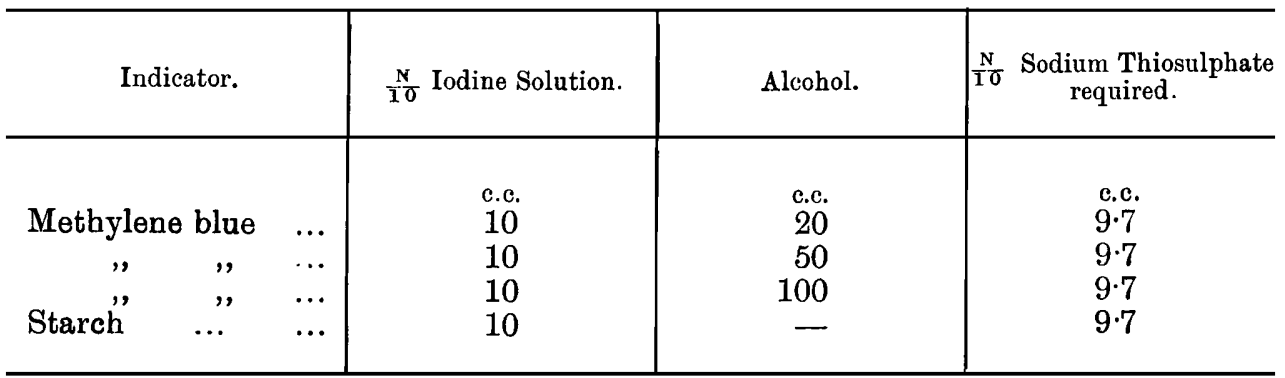

The introduction of chloroform or carbon tetrachloride does not affect the titration if the percentage of alcohol present is sufficient to prevent the organic solvent separating from the solution.

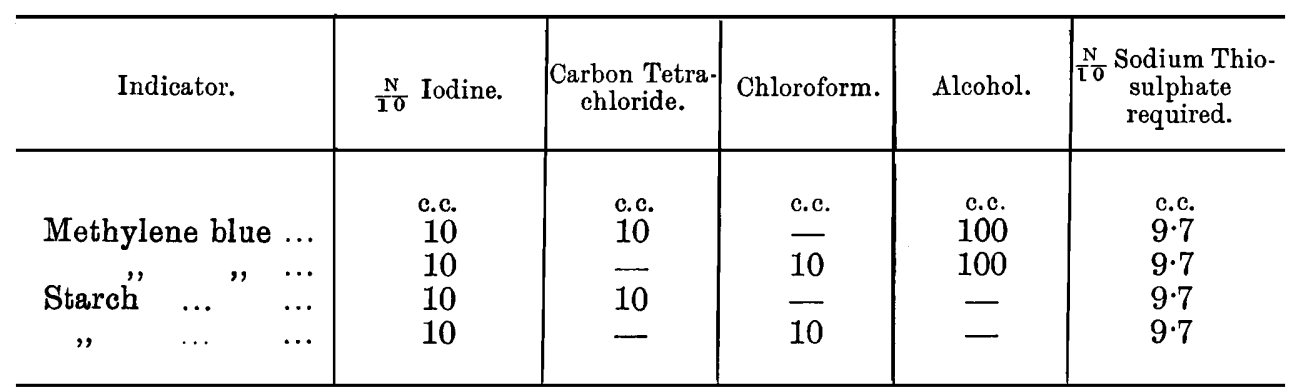

A solution of iodine in alcohol was prepared, having a concentration approximately decinormal; no potassium iodide was used.

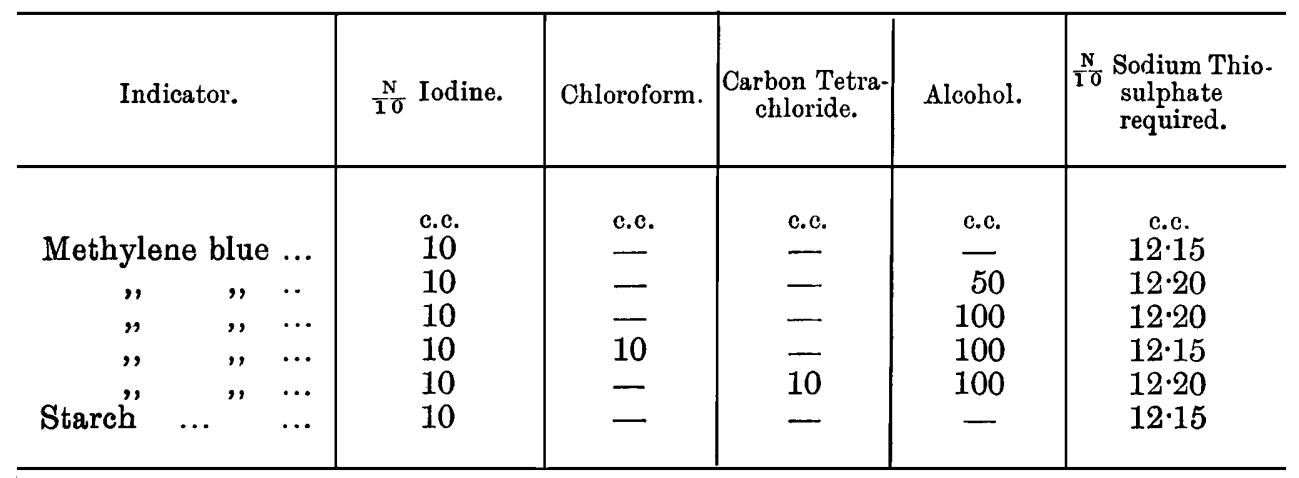


Before the check titration, in which starch was used as the indicator, was performed, potassium iodide solution was added to the alcoholic solution of iodine, and then a large volume of water, and the titration carried on in the usual manner.

For Wijs' solution an aqueous solution of potassium iodide was added, then alcohol until the whole formed a clear solution.

\begin{tabular}{|c|c|c|c|c|c|c|}
\hline Indicator. & $\begin{array}{c}\text { Wijs' } \\
\text { Solution. }\end{array}$ & $\begin{array}{c}\text { Carbon Tetra- } \\
\text { chloride. }\end{array}$ & $\begin{array}{l}\text { Chloro- } \\
\text { form. }\end{array}$ & $\begin{array}{l}\text { Potassium } \\
\text { Iodide. }\end{array}$ & Alcohol. & $\begin{array}{c}\mathrm{N} \text { Sodium } \\
\text { Thiosulphate } \\
\text { required. }\end{array}$ \\
\hline \begin{tabular}{cc}
\multicolumn{2}{c}{ Methylene blue } \\
,$"$, & $"$ \\
Starch & ...
\end{tabular} & $\begin{array}{l}\text { c.c. } \\
10 \\
10 \\
10 \\
10\end{array}$ & $\frac{\text { c.c. }}{10}$ & $\begin{array}{l}\frac{c . c}{10} \\
-\end{array}$ & $\begin{array}{l}\text { c.c. } \\
20 \\
20 \\
20 \\
20\end{array}$ & $\begin{array}{l}\text { c.c. } \\
100 \\
100 \\
100 \\
-\end{array}$ & $\begin{array}{c}\text { |c.c. } \\
19 \cdot 6 \\
19 \cdot 6 \\
19 \cdot 6 \\
19 \cdot 6\end{array}$ \\
\hline
\end{tabular}

Chemistry Department,

SCHOOL OF TECHNOLOGY, Manchester. 